\title{
Development of personalized treatments in lung cancer: focusing on the EGFR mutations and beyond
}

This article was published in the following Dove Press journal:

Lung Cancer:Targets and Therapy

14 August 2013

Number of times this article has been viewed

\author{
Kenichi Suda ${ }^{1,2}$ \\ Tetsuya Mitsudomi' \\ 'Division of Thoracic Surgery, \\ Department of Surgery, Kinki \\ University Faculty of Medicine, \\ Osaka-Sayama, Japan; ${ }^{2}$ Department \\ of Surgery and Science, Graduate \\ School of Medical Sciences, Kyushu \\ University, Fukuoka, Japan
}

\begin{abstract}
Lung cancers with epidermal growth factor receptor (EGFR) gene mutation account for $\sim 40 \%$ of adenocarcinoma in East Asians and $~ 15 \%$ of that in Caucasians, which makes them one of the most common molecularly defined lung cancer subsets. The role of EGFR mutation as a strong predictive biomarker of response to EGFR-tyrosine kinase inhibitors (TKIs) was finally confirmed by the biomarker analysis of Iressa Pan-Asian Study (IPASS). Since the 2004 discovery of EGFR mutation in lung cancer, the EGFR mutation and EGFR-TKI treatment have been widely studied. These include characteristics of lung cancers with $E G F R$ mutations; clinical efficacies and adverse effects of EGFR-TKIs in patients with EGFR-mutated lung cancers; development of novel EGFR-TKIs that may prolong progression-free survival of these patients or overcome resistance to first-generation EGFR-TKIs (gefitinib and erlotinib); optimal treatment schedules for EGFR-TKIs to delay emergence of resistance; molecular mechanisms of acquired resistance to EGFR-TKIs; treatment strategies after patients acquire resistance to EGFR-TKIs; and predictive biomarkers for EGFR-TKIs among patients with EGFR-mutated lung cancers. Some of these results are widely accepted, while others are apparent only in cell line models, preclinical animal models, or retrospective analyses (and sometimes conflict with each other). In this review, we summarize accumulated reports from the past decade, especially focusing on unanswered but important clinical questions in treating patients with $E G F R$-mutated lung cancers.
\end{abstract}

Keywords: epidermal growth factor receptor mutation, predictive biomarkers, personalized therapy, molecular target, adjuvant therapy, acquired resistance

\section{Introduction}

Next year, 2014, will mark the tenth anniversary of the discovery of somatic mutations of the epidermal growth factor receptor (EGFR) gene in non-small-cell lung cancers. The EGFR mutation is of both clinical and investigational interest because its presence strongly predicts efficacy of EGFR-tyrosine kinase inhibitors (TKIs) that have been applied in clinic a few years before.

In the decade after this discovery, clinicians and researchers have found clinical, pathological, and prognostic characteristics of EGFR-mutated lung cancers, and began several clinical trials, enrolling "selected" patients. These trials ${ }^{1-4}$ showed the superiority of EGFR-TKIs in progression-free survival (PFS) compared with platinumdoublet chemotherapy, which had been the gold-standard regimen, in patients with EGFR-mutated lung cancers.

However, this clinical success has invited other questions for researchers: (1) why does EGFR-TKI efficacy vary among patients with EGFR-mutated lung cancers?; (2) why do patients who show dramatic initial responses acquire resistance, and
Division of Thoracic Surgery,

Department of Surgery, Kinki University Faculty of Medicine, 377-2 Ohno-Higashi, Osaka-Sayama 589-85I I, Japan

Tel +8I 72366022 I

Fax +8I 72367777 I

Email ascaris@surg2.med.kyushu-u.ac.jp submit your manuscript $\mid$ www.dovepress.com

Dovepress

http://dx.doi.org// 0.21 47/LCTT.S49603
Lung Cancer:Targets and Therapy 201 3:4 43-53

(c) (i) (-) 2013 Suda and Mitsudomi. This work is published by Dove Medical Press Ltd, and licensed under Creative Commons Attribution - Non Commercial (unported, v3.0) permission from Dove Medical Press Ltt, provided the work is properly attributed. Permissions beyond the scope of the License are administered by Dove Medical Press Ltd. Information on how to permisssion from Dove Medical Press Ltd, provided the work is properly attrbuted
request permission may be found at: http://www.dovepress.com/permissions.php 
how can this be avoided or overcome?; (3) what is the best EGFR-TKI for a particular patient?; and (4) what is the most appropriate EGFR-TKI treatment schedule?

In this review, we summarize accumulated studies on EGFR-mutated lung cancers and EGFR-TKIs from the last 10 years. In addition, we discuss the further issues that must be addressed to optimize outcomes of patients with EGFRmutated lung cancers.

\section{Basic EGFR information}

EGFR is a transmembrane receptor tyrosine kinase (Figure 1). Upon binding to its ligands (epidermal growth factor, transforming growth factor alpha, amphiregulin, etc), EGFR forms homodimers or heterodimers with the other family members (ERBB2, ERBB3, or ERBB4), ${ }^{5}$ which stimulates intrinsic receptor tyrosine kinase activity and triggers autophosphorylation of specific tyrosine residues within their cytoplasmic regulatory domains. These phosphorylated tyrosine residues activate several signaling pathways, including mitogen-activated protein kinase (MAPK) pathway, phosphatidylinositol 3-kinase (PI3K)/AKT pathway, and the signal transducer and activator of transcription pathways. These pathways promote cell proliferation, migration and metastasis, evasion from apoptosis, or angiogenesis, all of which are associated with cancer phenotypes.

Because various cancers, including lung cancers, often overexpress EGFR, which is reportedly associated with poor prognosis, ${ }^{6}$ EGFR is regarded as a promising molecular target in cancer therapy. However, all four Phase III trials that enrolled unselected patients and compared chemotherapy plus EGFR-TKI to chemotherapy alone gave negative results for addition of the EGFR-TKIs. ${ }^{7-10}$ In addition, one EGFR-TKI, gefitinib, even failed to show survival advantage over placebo in unselected previously treated

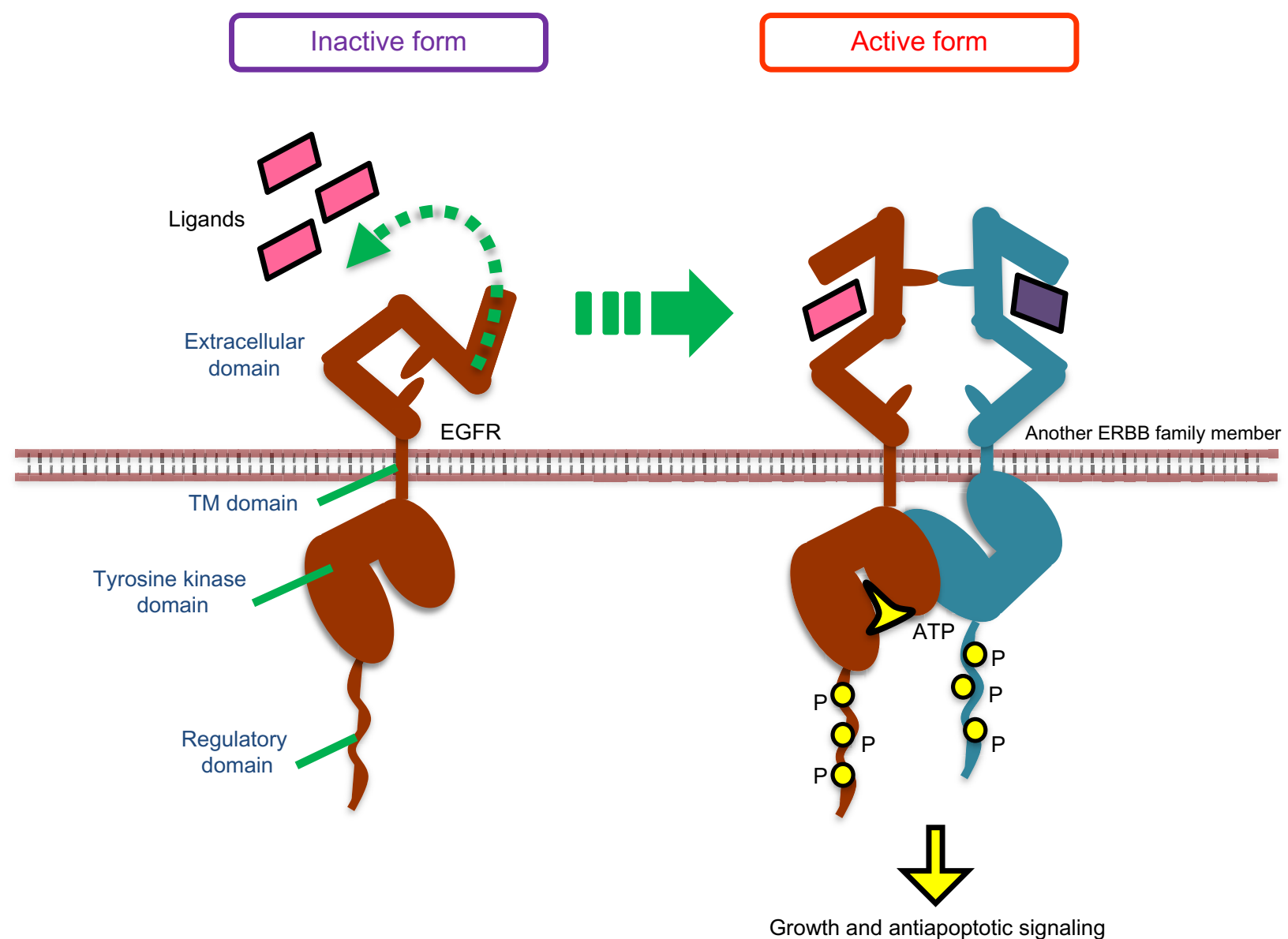

Figure I Structure and activation mechanism of epidermal growth factor receptor (EGFR).

Notes: The EGFR protein consists of extracellular, transmembrane, tyrosine kinase, and regulatory domains. EGFR undergoes conformation changes when a specific ligand binds to its extracellular domain, and EGFR forms homodimers or heterodimers with the other ERBB family members (ERBB2, ERBB3, or ERBB4). In doing so, their respective kinase domains dimerize asymmetrically, in a tail-to-head orientation, which stimulates intrinsic tyrosine kinase activity of the receptors and triggers autophosphorylation of specific tyrosine residues within the cytoplasmic regulatory domains. These phosphorylated tyrosine residues serve as specific binding sites for several adaptor proteins, inducing proliferative or antiapoptotic signaling pathways, such as mitogen-activated protein kinase, phosphatidylinositol 3-kinase/AKT, and the signal transducer and activator of transcription pathways.

Abbreviations: TM, transmembrane; P, indicates phosphorylation of tyrosine residues; ATP, adenosine triphosphate. 
patients. ${ }^{11}$ These failures in early-phase EGFR-TKI therapy development ironically support the importance of biomarkerbased treatment in lung cancers.

\section{Established evidence of EGFR- mutated lung cancers and EGFR- TKI treatment}

EGFR somatic activating mutations, which occur in the EGFR-tyrosine kinase domain, were discovered in 2004 by two independent groups in Boston, MA, USA. ${ }^{12,13}$ EGFR mutations usually occur in the first four exons of tyrosine kinase domain (exons 18-21) and reportedly induce ligandindependent activation of EGFR, followed by activation of downstream proliferative and antiapoptotic signaling.

Lung cancers with EGFR mutation account for $\sim 40 \%$ of adenocarcinoma in East Asians and $\sim 15 \%$ of those in Caucasians, ${ }^{14}$ which makes them one of the most common molecularly defined lung cancers subset. The role of EGFR mutation as a strong predictive biomarker of response to EGFR-TKI treatment has been reported in several retrospective analyses, ${ }^{15}$ and finally confirmed by the biomarker analyses of Iressa Pan-Asian Study (IPASS). ${ }^{16}$

For chemotherapy-naïve patients with $E G F R$-mutated lung cancers, six Phase III trials have proved PFS of EGFRTKI treatment (gefitinib, erlotinib, or afatinib) is superior to that of platinum-doublet chemotherapy (Table 1). ${ }^{1-4,17,18}$ Although these prospective trials could not prove the power of EGFR-TKIs to prolong overall survival (OS) because of a high crossover rate between the two arms, two retrospective analyses observed that EGFR-TKI treatment was an independent favorable predictor for OS among patients with $E G F R$-mutated lung cancers but not in those without $E G F R$ mutation. ${ }^{19,20}$ Because median survival time in the 2002 Eastern Cooperative Oncology Group (ECOG) 1594 study, which compared four different platinum-doublet chemotherapies, ranged from 7.4 to 8.1 months, ${ }^{21}$ median survival time $>24$ months, as shown in Table 1, is extremely noteworthy.

On the other hand, clinicians experienced that not all patients with $E G F R$-mutated lung cancers responded equally to EGFR-TKIs. Accumulated data show that patients harboring the two most common mutations, exon 19 deletion mutation and L858R point mutation (exon 21), respond very well, followed by G719X point mutation (exon 18) and L861Q point mutation (exon 21), whereas tumors with exon 20 insertion mutation show intrinsic resistance to firstgeneration EGFR-TKIs, gefitinib and erlotinib. ${ }^{15}$ Coexistence of pretreatment T790M gatekeeper mutation (in the section: How does acquired gefitnib-erlotinib resistance occur after promising initial responses?), found by direct sequencing in $\sim 0.5 \%$ of lung cancers with activating EGFR mutation, ${ }^{22}$ reportedly also causes inherent resistance. The role of less common EGFR mutations as predictors for EGFR-TKI response is unclear because of their scarcity. ${ }^{23,24}$

The use of EGFR mutation status as a predictive biomarker requires knowing whether all cancer cells in one lung cancer patient harbor the same EGFR mutational status, ie, if the EGFR mutational status is homogenous or not. Because EGFR mutations are also identified in precursor lesions of lung adenocarcinoma or lung adenocarcinoma

Table I Summary of PFS and OS in prospective studies that compared EGFR-TKIs with platinum-doublet chemotherapies

\begin{tabular}{|c|c|c|c|c|c|c|c|c|}
\hline \multirow[t]{2}{*}{ Study } & \multirow[t]{2}{*}{ Patient group } & \multirow[t]{2}{*}{ EGFR-TKI } & \multirow[t]{2}{*}{$\mathbf{N}$} & \multicolumn{2}{|c|}{ PFS (months) } & \multirow[t]{2}{*}{ HR for PFS $(95 \% \mathrm{Cl})$} & \multicolumn{2}{|c|}{ OS (months) } \\
\hline & & & & TKI & Chemotherapy & & TKI & Chemotherapy \\
\hline \multicolumn{9}{|c|}{ I. Subset analyses of patients selected by clinical background } \\
\hline IPASS 86 & Asian & Gefitinib & 261 & 9.5 & 6.3 & $0.48(0.36-0.64)$ & 21.6 & 21.9 \\
\hline First-SIGNAL ${ }^{87}$ & Korean & Gefitinib & 42 & 8.4 & 6.7 & $0.61(0.31-1.22)$ & 30.6 & 26.5 \\
\hline \multicolumn{9}{|c|}{ 2. Phase III trials for patients selected by EGFR mutation } \\
\hline NEJ002 ${ }^{2}$ & Japanese & Gefitinib & 228 & 10.8 & 5.4 & $0.32(0.24-0.44)$ & 27.7 & 26.6 \\
\hline WJTOG3405' & Japanese & Gefitinib & 172 & 9.6 & 6.6 & $0.52(0.38-0.72)$ & 35.5 & 38.8 \\
\hline OPTIMAL ${ }^{4}$ & Chinese & Erlotinib & 154 & 13.7 & 4.6 & $0.16(0.10-0.26)$ & 22.7 & 28.9 \\
\hline EURTAC 3 & Caucasian & Erlotinib & 173 & 9.7 & 5.2 & $0.37(0.25-0.54)$ & 19.3 & 19.5 \\
\hline \multirow[t]{2}{*}{ LUX-Lung $3^{17}$} & Caucasian $26 \%$ & Afatinib & 345 & 11.1 & 6.9 & $0.58(0.43-0.78)$ & $N / A$ & $N / A$ \\
\hline & Asian $72 \%$ & & & & & & & \\
\hline LUX-Lung $6^{18}$ & Asian & Afatinib & 364 & 13.7 & 5.6 & $0.28(0.20-0.39)$ & N/A & $N / A$ \\
\hline
\end{tabular}

Abbreviations: $\mathrm{Cl}$, confidence interval; EGFR, epidermal growth factor receptor; HR, hazard ratio; N/A, not applicable; OS, overall survival; PFS, progression-free survival; TKI, tyrosine kinase inhibitor; IPASS, IRESSA Pan-Asian Study; First-SIGNAL, First-line Single Agent Iressa versus Gemcitabine and cisplatin Trial in Never-smokers with Adenocarcinoma of the Lung; NEJ, North East Japan; WJTOG, West Japan Thoracic Oncology Group; OPTIMAL, A Randomized, Open-label, Multi-center Phase III Study of Erlotinib Versus Gemcitabine/Carboplatin in Chemo-naive Stage III/IV Non-Small Cell Lung Cancer Patients With EGFR Exon 19 or 21 Mutation; EURTAC, European Randomised Trial of Tarceva vs. Chemotherapy; LUX-Lung 3, LUX-Lung 6, A Randomised, Open-label, Phase III Study of BIBW 2992 Versus Chemotherapy as First-line Treatment for Patients With Stage IIIB or IV Adenocarcinoma of the Lung Harbouring and EGFR Activating Mutation. 
in situ, ${ }^{25}$ this mutation is assumed to occur in early phases of lung carcinogenesis, indicating that all lung cancer cells retain the same $E G F R$ mutation. However, early reports observed discordant EGFR mutational status between primary tumors and lymph node metastases, and others observed intratumoral heterogeneity of EGFR mutations. ${ }^{26}$ As the cause of such heterogeneity of EGFR mutation, Yatabe, one of our principal coinvestigators, considered contamination of normal cells (eg, fibroblasts) and differences in gene copy number or expression level of mutated $E G F R$, if low sensitivity methods were used. To confirm this supposition, Yatabe et al performed a detailed analysis using high-sensitivity methods and identified no discordant mutation patterns among 77 paired primary and metastatic site samples or among 54 primary and recurrent tumor pairs. ${ }^{26}$ In addition, to examine intratumor heterogeneity, three samples each from 50 lung cancers and 100 samples each from an additional five tumors were examined; the same mutations throughout each individual tumor were identified. ${ }^{26}$

These widely accepted investigations have changed treatment strategies for patients with EGFR-mutated lung cancers and improved their outcomes. However, these successes have also raised several clinical questions and problems.

\section{Why does the efficacy of EGFR-TKIs vary among patients with lung cancers with sensitive EGFR mutations?}

Disease control rates of gefitinib or erlotinib for patients with lung cancers with sensitive EGFR mutations in firstline Phase III studies were reported to be $93 \% \sim 97 \%,{ }^{1,3,4}$ which implies that 3\% 7\% of EGFR-mutated lung cancers are inherently resistant to EGFR-TKIs even though they harbor "sensitive" EGFR mutations. Some researchers have focused on the molecular mechanisms of inherent resistance. As downregulation of the PI3K-AKT pathway is required for EGFR-TKI-induced apoptosis in EGFR-mutated lung cancers, ${ }^{27}$ and inactivation of PTEN is a common cause of PI3K pathway activation in human cancers, ${ }^{28} \mathrm{PTEN}$ has been included as a candidate molecule in inherent resistance to EGFR-TKIs. An example of in vitro inherent resistance is seen in the H1650 lung cancer cell line, which harbors an EGFR mutation and homozygous deletion of PTEN. PTEN reconstitution by stable retroviral expression increased susceptibility to TKI-induced apoptosis in this cell line. ${ }^{29}$ In addition, in a recent analysis using inherent resistance clinical specimens, Yano et al observed that high-level expression of hepatocyte growth factor, a ligand of MET proto-oncogene product, was detected in 29\% of tumors and MET gene amplification in 4\%, suggesting the participation of these molecules in intrinsic EGFR-TKI resistance in patients with EGFRmutated lung cancers. ${ }^{30}$ Clinical relevance of these molecules on inherent resistance to gefitinib or erlotinib, and treatment strategies to overcome these resistance mechanisms, should be determined in the future.

Among patients who respond to gefitinib or erlotinib, some show shorter PFS. Why do some EGFR-mutated lung cancers easily acquire resistance to EGFR-TKIs? To explain this phenomenon, Maheswaran et al analyzed pretreatment tumor specimens for a preexisting small population of cancer cells with T790M gatekeeper mutation (a resistant mutation described in the section: How does acquired gefitinib/ erlotinib resistance occur after promising initial responses?) using a high-sensitivity method. Interestingly, pretreatment minor clones with T790M mutation were detected in $38 \%$ of EGFR-mutated lung cancers, and correlated with reduced PFS after EGFR-TKI treatment. ${ }^{31}$ Rosell et al also identified pretreatment minor clones with T790M mutation in $35 \%$ of EGFR-mutated lung cancers, and observed shorter PFS in patients with pretreatment T790M mutation. ${ }^{32}$ Most recently, Su et al analyzed pretreatment T790M mutation using mass spectrometry and next-generation sequencing, and found pretreatment T790M mutation to again be an independent predictor of decreased PFS after EGFR-TKI treatment. ${ }^{33}$

Meanwhile, as a predictive biomarker of EGFR-TKI response among patients with lung cancers with sensitive EGFR mutation, Faber et $\mathrm{al}^{34}$ and $\mathrm{Ng}$ et $\mathrm{al}^{35}$ studied the BCL2interacting mediator of cell death (BIM), a proapoptotic BCL-2 family protein, upregulation of which is required for TKI-induced apoptosis. These investigations found low BIMextra long (EL) isoform expression and an intronic deletion polymorphism of BIM that provided decreased expression of BIM-EL as predictors of diminished response to EGFR-TKIs in EGFR-mutated lung cancers. ${ }^{34,35}$ Consistent with these results, Nakagawa et al observed that two EGFR-mutated lung cancer cell lines with BIM deletion polymorphism (PC3 and HCC2279) showed low susceptibility to gefitinib-induced apoptosis. ${ }^{36}$ Interestingly, the intronic deletion polymorphism of $B I M$ also conferred low sensitivity to imatinib in ABL1 kinase-driven chronic myeloid leukemia. ${ }^{35}$

On the other hand, Bivona et al identified FAS and NF-kB signaling as a suppressor of EGFR-TKI-induced cell death. ${ }^{37}$ Following this observation, they analyzed $\mathrm{I} \kappa \mathrm{B}$ expression in $E G F R$-mutated lung cancers and found that low IкB expression (high NF-kB activation state) was predictive of worse 
PFS, while IאB expression did not predict PFS among patients treated with chemotherapy. ${ }^{37}$ Other studies have implied that low expression of LIM-domain-only 4 (LMO4) ${ }^{38}$ or of PTEN ${ }^{39}$ predicts a poor response to EGFR-TKI treatment.

These results are, however, controversial. For example, Fujita et al found pretreatment minor clones with T790M mutation in $79 \%$ of $E G F R$-mutated lung cancers, but this did not predict the response to gefitinib treatment. ${ }^{40}$ Rosell et al also saw no difference in PFS between patients with and without pretreatment minor clones with T790M mutation in the erlotinib arm of the EURTAC trial. ${ }^{41}$ Meanwhile, Lee et al analyzed 193 patients with EGFR-mutated lung cancers for $B I M$ intronic deletion polymorphism and found that the $B I M$ polymorphism did not predict PFS after EGFR-TKI treatment. ${ }^{42}$ Such discrepancies might be caused by overlapping and interacting of molecular biomarkers. Rosell et al found that pretreatment minor clones with T790M mutation and increased BRCA1 mRNA levels both significantly predicted a poor response to EGFR-TKI treatment, whereas low $B R C A 1$ levels neutralized the negative effect of pretreatment T790M mutation. ${ }^{32}$ Table 2 summarizes these studies. Comprehensive analyses for these molecular biomarker candidates are needed to identify the most reliable predictive marker(s) for EGFR-TKI treatment.

\section{How does acquired gefitinib/ erlotinib resistance occur after promising initial responses?}

Despite initial dramatic response, almost all patients with $E G F R$-mutated lung cancers eventually develop acquired resistance to gefitinib or erlotinib. A clinical definition of acquired resistance was proposed by Jackman et al in
$2010,{ }^{43}$ and mechanisms underlying acquired resistance have been extensively analyzed. Acquisition of T790M gatekeeper mutation of the EGFR, which substitutes methionine for threonine at amino acid position $790,{ }^{44,45}$ is the most common mechanism of acquired resistance, reportedly up to $68 \%-83.3 \%$ if high-sensitivity method is used..$^{33,46}$ Initially, the larger methionine residue was thought to sterically block binding of gefitinib or erlotinib; however, a later study found increased ATP affinity of EGFR with T790M mutation as the mechanism of resistance. ${ }^{47}$ Several EGFR-TKIs that can bind to EGFR with T790M are now under development (as described in the section: What is the most appropriate EGFR-TKI?).

The second candidate of acquired resistance mechanism is MET activation, either by gene amplification ${ }^{48,49}$ or by high expression of the ligand (HGF). ${ }^{50}$ Acquired resistance in in vitro models by MET activation is highly responsive to a combination of EGFR-TKI and MET-TKI, ${ }^{48,50,51}$ but these results have not been confirmed in clinical settings. MET reportedly mediates several miRNAs, (miR-30b, miR-30c, miR-221, miR-222, miR-103, and miR-203) that affect gefitinib-induced apoptosis and epithelial-to-mesenchymal transition (EMT) of lung cancer cells. ${ }^{52}$

Other candidates of acquired resistance molecular mechanisms against EGFR-TKIs in EGFR-mutated lung cancers are not yet evaluated well in clinical samples, identified only in acquired resistance in vitro models or in observation of small numbers of clinical specimens obtained after EGFRTKI treatment failure. Those resistant mechanisms include PTEN downregulation; CRKL amplification; NFkB signaling activation; AXL activation; HER2 amplification; reactivation of ERK signaling by either an amplification of MAPK1 or

Table 2 Predictive biomarker candidates for poor response to gefitinib/erlotinib in patients with EGFR-mutated lung cancers

\begin{tabular}{|c|c|c|c|}
\hline \multirow[t]{2}{*}{ Candidate biomarkers } & \multirow[t]{2}{*}{ Molecular mechanism } & \multicolumn{2}{|c|}{ Predictive biomarker for poor response } \\
\hline & & Pros & Cons \\
\hline Preexistence of small population & TKI treatment select preexistence drug-resistant cells & Maheswaran et $\mathrm{al}^{31}$ & Fujita et $\mathrm{al}^{40}$ \\
\hline of cancer cells with T790M & & Rosell et a ${ }^{32, \mathrm{a}}$ & Rosell et $\mathrm{al}^{4 \mathrm{l}}$ \\
\hline drug-resistant mutation & & Su et $\mathrm{a}^{33}$ & \\
\hline Low BIM-EL expression & $\begin{array}{l}\text { Upregulation of BIM (BIM-EL isoform) is required } \\
\text { for TKI-induced apoptosis }\end{array}$ & Faber et $\mathrm{a}^{34}$ & \\
\hline BIM deletion polymorphism & $\begin{array}{l}\text { The deletion polymorphism provides decreased } \\
\text { expression of BIM-EL }\end{array}$ & $\begin{array}{l}\text { Ng et al }{ }^{35} \\
\text { Isobe et al }{ }^{88}\end{array}$ & Lee et $\mathrm{al}^{42}$ \\
\hline Low IKB expression & $\begin{array}{l}\text { IKB suppresses NFKB activation that suppresses } \\
\text { TKI-induced cell death }\end{array}$ & Bivona et $\mathrm{al}^{37}$ & \\
\hline $\begin{array}{l}\text { Intermediate/high BRCAI } \\
\text { expression }\end{array}$ & $\begin{array}{l}\text { DNA repair enzyme that may also repair } \\
\text { TKI-induced DNA breakage }\end{array}$ & Rosell et $\mathrm{al}^{32, \mathrm{a}}$ & \\
\hline Low LMO4 expression & Negative regulator of BRCAI function & Karachaliou et $\mathrm{a}^{38, \mathrm{a}}$ & \\
\hline
\end{tabular}

Note: a These investigations analyzed the same cohort of patients.

Abbreviations: BIM, BCL2-interacting mediator of cell death; EGFR, epidermal growth factor receptor; EL, extra long; LMO4, LIM-domain-only 4; TKI, tyrosine kinase inhibitor; BRCAI, breast cancer I early onset. 
by downregulation of negative regulators of ERK signaling; $B R A F$ mutation; loss of EGFR mutant allele; EMT including stem cell-like features; or conversion to small-cell lung cancer. ${ }^{53-60}$ Several reports that analyzed clinical specimens suggest that main molecular mechanisms of acquired resistance basically occur in a mutually exclusive fashion (as might be represented in a pie chart), ${ }^{51,53,61}$ indicating the importance of molecular analyses after a lung cancer patient acquires resistance to first-line treatment with EGFR-TKI.

\section{What is the most appropriate EGFR-TKI?}

Because T790M secondary mutation is the most common acquired resistance mechanism to gefitinib or erlotinib, and EGFR-mutated lung cancers often harbor this mutation as a minor clone prior to treatment, several EGFR-TKIs that can suppress T790M mutation are now under development. To overcome T790M mutation, irreversible EGFR-TKIs, such as afatinib or dacomitinib, which covalently bond to cysteine 797 of EGFR, were initially developed. As a firstline therapy, afatinib showed superior PFS ${ }^{17,18}$ compared with cisplatin/pemetrexed or compared with cisplatin/gemcitabine in patients with EGFR-mutated lung cancers (Table 1). However, it remains unclear which EGFR-TKI (gefitinib, erlotinib, or afatinib) is the most appropriate for first-line EGFR-TKI therapy. These EGFR-TKIs differ in efficacy and adverse effects; results of major prospective EGFR-TKI trials in a first-line setting are summarized in Tables 1 and 3 for efficacy and adverse effects, respectively. Many clinical trials analyzing the differences between these EGFR-TKIs are currently underway (eg, WJOG 5108 L, LUX-Lung 8, and ARCHER studies).

Irreversible EGFR-TKIs, so-called second-generation EGFR-TKIs, were also expected to overcome acquired resistance after treatment failure of gefitinib or erlotinib, because they showed in vitro activity in cancer cells with T790M mutation, ${ }^{62,63}$ or exon 20 insertion mutations that confer de novo resistance to gefitinib or erlotinib, ${ }^{64}$ at clinically achievable concentrations. However, these compounds are also active for wild-type EGFR; ${ }^{62,63}$ therefore, dose limitation due to inhibition of wild-type EGFR is predicted to result in inadequate clinical activity against cancer cells harboring EGFR T790M mutation. Indeed, the LUX-Lung 1 study, which enrolled patients who received at least 12 weeks of gefitinib or erlotinib and experienced treatment failure, found no OS advantage in the afatinib arm compared with placebo. ${ }^{65}$

To overcome this drawback, chemical libraries were screened to find compounds that selectively inhibit mutant

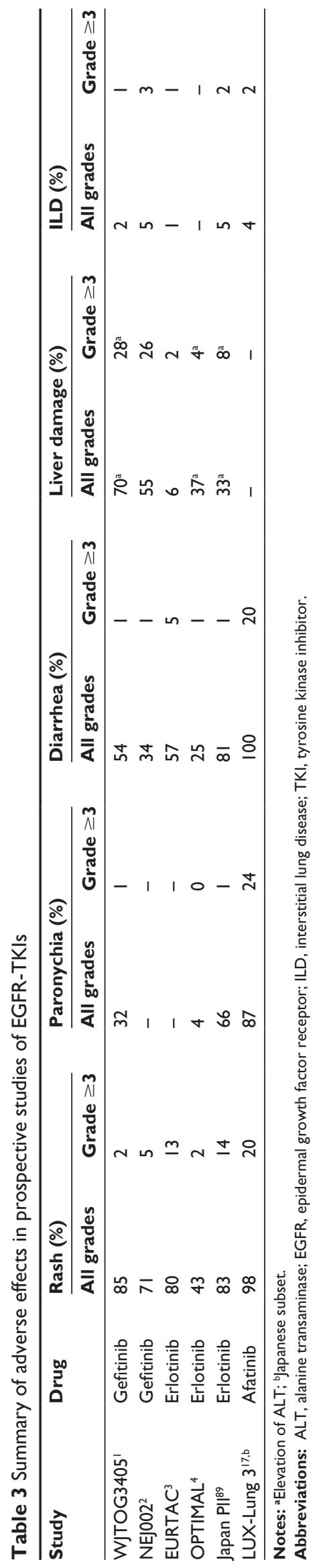


EGFR, including T790M mutation, while sparing wild-type EGFR. These EGFR-TKIs are called "T790M-specific" or "third-generation" EGFR-TKIs, and several compounds are now under development. ${ }^{66-68}$ Although no results from large clinical trials for these compounds have been reported, these T790M-specific EGFR-TKIs have shown promising results in preclinical settings, and one, CO-1686, recently showed tumor shrinkage in patients with EGFR-mutated lung cancer after acquisition of T790M mutation. ${ }^{69}$

\section{What is the most appropriate treatment schedule for EGFR-TKI?}

For patients with EGFR-mutated lung cancers, EGFR-TKIs are usually administered as continuous treatment. However, the superiority of this treatment schedule is not confirmed. To address this question, Chmielecki et al analyzed isogenic EGFR-TKI-sensitive and EGFR-TKI-resistant (due to T790M mutation) pairs of cell lines that mimic the behavior of human tumors. In their analyses, T790M-mediated EGFR-TKI-resistant cells showed slower growth compared with sensitive cells in a drug-free condition. Therefore, they evaluated an intermittent high-dose pulse of erlotinib (or afatinib) in conjunction with a continuous low-dose administration of erlotinib, and proposed that this treatment schedule may delay the acquisition of EGFR-TKI resistance. ${ }^{70}$ An intermittent treatment schedule has also been suggested in preclinical models of $B R A F$-mutated melanoma; ${ }^{71}$ however, it is not clear if these treatment schedules can be applicable to all patients with EGFR-mutated lung cancers.

\section{Treatment strategies after acquisition of resistance to gefitinib/erlotinib}

Although, theoretically, resistance mechanism-based treatments are desired, in clinical practice, EGFR-TKI is usually converted to cytotoxic chemotherapy after lung cancer patients acquire resistance to gefitinib or erlotinib. In the NEJ002 trial that compared gefitinib with carboplatin/ paclitaxel in first-line settings, as much as $65 \%$ of the patients received chemotherapy, and $62 \%$ of this was platinum-based, as the second-line treatment in patients who were originally allocated to the gefitinib group. ${ }^{72}$

After acquisition of resistance to EGFR-TKIs, clinicians must pay attention to a phenomenon called "disease flare." 73 This phenomenon is reported to occur in 14 of 61 patients $(23 \%)$, and is defined as hospitalization or death attributable to disease progression. ${ }^{74}$ Disease flare has also been experimentally mimicked. ${ }^{70}$ Results suggest that patients may benefit from continued treatment with an EGFR-TKI, even after developing T790M-mediated resistance (beyond progressive disease [PD]). This concept is now being tested in several clinical trials, including IMPRESS, in which patients with acquired resistance to gefitinib are randomized between cisplatin/pemetrexed and cisplatin/pemetrexed plus gefitinib treatment (ClinicalTrials.gov, number NCT01544179). ${ }^{75}$

Several auspicious candidate treatments other than conversions to chemotherapy with or without EGFR-TKIs have been suggested to overcome acquired resistance to gefitinib or erlotinib. One of these candidates is combination of an antiEGFR antibody and an irreversible EGFR-TKI, afatinib. AntiEGFR antibodies bind to EGFR and induce endocytosis and depletion of total EGFR from cell surface. Combination of an irreversible EGFR-TKI, afatinib, with cetuximab was assessed in in vivo models and achieved marked shrinkage of erlotinibresistant tumors with T790M mutation. ${ }^{76}$ Following this result, a Phase I/II study of afatinib combined with cetuximab was conducted, enrolling100 patients with clinically defined acquired resistance to EGFR-TKIs. Amazingly, disease control rate and response rate were $94 \%$ and $40 \%$, respectively, and, interestingly, the response was similar in both T790M+ (38\%) and T790M- (47\%) tumors. ${ }^{77}$ These results may suggest that most lung cancers depend on the EGFR signaling pathway even after acquisition of resistance to EGFR-TKIs, regardless of the presence of T790M mutation.

As a completely different approach, heat shock protein 90 (Hsp90) has been reported as a candidate molecule that may overcome acquired resistance to EGFR-TKIs. Hsp90 is a $90 \mathrm{kDa}$ molecular chaperone that is required for folding, stabilization, and function of proteins, including several oncogene products such as EGFR, MET, and EML4-ALK. Some studies suggest that Hsp90 inhibition may be beneficial for patients with acquired resistance to EGFR-TKIs. ${ }^{78,79}$

\section{EGFR-TKIs in adjuvant setting after surgical resection}

Platinum-doublet adjuvant chemotherapy, the current standard of care for pathological stage II-III non-small-cell lung cancer patients after "curative" resection, improves the 5-year survival rate by only $5.4 \%$ compared with surgery alone. ${ }^{80}$ Because pulmonary resection provides abundant tumor tissues for analyses, several biomarker-based clinical trials in adjuvant settings have been performed or are ongoing. ${ }^{81}$ Some of these trials include EGFR status for selection of adjuvant chemotherapy. Although the prematurely terminated BR.19 trial could not show the efficacy of adjuvant gefitinib 
therapy compared with placebo, even in the subset of patients with EGFR mutation, ${ }^{82}$ a retrospective study found adjuvant EGFR-TKI to be associated with a lower risk of recurrence. ${ }^{83}$ To confirm the role of adjuvant EGFR-TKI prospectively in patients with EGFR-mutated lung cancers, the ongoing, Phase III IMPACT trial is comparing gefitinib with cisplatin plus vinorelbine. ${ }^{84}$ Also, to confirm the efficacy of biomarkertailored adjuvant therapy, several ongoing Phase III trials ${ }^{82}$ are comparing customized and standard treatment. In the TASTE study, ${ }^{85}$ patients are assigned to three groups the a customized arm, with erlotinib for those with EGFR mutations, cisplatin plus pemetrexed for those without $E G F R$ mutation and low ERCC1, and no treatment for those without EGFR mutation and high ERCC1, while all patients in the standard arm receive cisplatin plus pemetrexed.

\section{Conclusion}

Although the prognosis of patients with EGFR-mutated lung cancers has dramatically improved over the past decade, many questions remain. Research must continue to seek the best treatments for patients with EGFR-mutated lung cancers. We hope this review aids many clinicians and researchers in understanding advances in this area and leads to better clinical trials and translational research in the next decade.

\section{Disclosure}

Dr Suda has no relevant financial interests to disclose. Dr Mitsudomi has declared the following financial relationships: lecture fees from AstraZeneca, Chugai, Pfizer, BoehringerIngelheim, and Taiho; research support grants from AstraZeneca, Pfizer, Eli-Lilly, Boehringer-Ingelheim, and Taiho; and consultation fees from AstraZeneca, Chugai, Roche, Boehringer-Ingelheim, Pfizer, Kyowa-Hakko Kirin, Novartis, Clovis, and Synta. The authors report no other conflicts of interest in this work.

\section{References}

1. Mitsudomi T, Morita S, Yatabe Y, et al; West Japan Oncology Group. Gefitinib versus cisplatin plus docetaxel in patients with non-small-cell lung cancer harbouring mutations of the epidermal growth factor receptor (WJTOG3405): an open label, randomised phase 3 trial. Lancet Oncol. 2010;11(2):121-128.

2. Maemondo M, Inoue A, Kobayashi K, et al; North-East Japan Study Group. Gefitinib or chemotherapy for non-small-cell lung cancer with mutated EGFR. N Engl J Med. 2010;362(25):2380-2388.

3. Rosell R, Carcereny E, Gervais R, et al; Spanish Lung Cancer Group in collaboration with Groupe Français de Pneumo-Cancérologie and Associazione Italiana Oncologia Toracica. Erlotinib versus standard chemotherapy as first-line treatment for European patients with advanced EGFR mutation-positive non-small-cell lung cancer (EURTAC): a multicentre, open-label, randomised phase 3 trial. Lancet Oncol. 2012;13(3):239-246.
4. Zhou C, Wu YL, Chen G, et al. Erlotinib versus chemotherapy as first-line treatment for patients with advanced EGFR mutation-positive non-smallcell lung cancer (OPTIMAL, CTONG-0802): a multicentre, open-label, randomised, phase 3 study. Lancet Oncol. 2011;12(8):735-742.

5. Hynes NE, Lane HA. ERBB receptors and cancer: the complexity of targeted inhibitors. Nat Rev Cancer. 2005;5(5):341-354.

6. Selvaggi G, Novello S, Torri V, et al. Epidermal growth factor receptor overexpression correlates with a poor prognosis in completely resected non-small-cell lung cancer. Ann Oncol. 2004;15(1):28-32.

7. Giaccone G, Herbst RS, Manegold C, et al. Gefitinib in combination with gemcitabine and cisplatin in advanced non-small-cell lung cancer: a phase III trial - INTACT 1. J Clin Oncol. 2004;22(5):777-784.

8. Herbst RS, Prager D, Hermann R, et al; TRIBUTE Investigator Group. TRIBUTE: a phase III trial of erlotinib hydrochloride (OSI-774) combined with carboplatin and paclitaxel chemotherapy in advanced non-small-cell lung cancer. J Clin Oncol. 2005;23(25):5892-5899.

9. Herbst RS, Giaccone G, Schiller JH, et al. Gefitinib in combination with paclitaxel and carboplatin in advanced non-small-cell lung cancer: a phase III trial - INTACT 2. J Clin Oncol. 2004;22(5):785-794.

10. Gatzemeier U, Pluzanska A, Szczesna A, et al. Phase III study of erlotinib in combination with cisplatin and gemcitabine in advanced non-small-cell lung cancer: the Tarceva Lung Cancer Investigation Trial. J Clin Oncol. 2007;25(12):1545-1552.

11. Thatcher N, Chang A, Parikh P, et al. Gefitinib plus best supportive care in previously treated patients with refractory advanced nonsmall-cell lung cancer: results from a randomised, placebo-controlled, multicentre study (Iressa Survival Evaluation in Lung Cancer). Lancet. 2005;366(9496):1527-1537.

12. Lynch TJ, Bell DW, Sordella R, et al. Activating mutations in the epidermal growth factor receptor underlying responsiveness of non-small-cell lung cancer to gefitinib. N Engl J Med. 2004;350(21):2129-2139.

13. Paez JG, Jänne PA, Lee JC, et al. EGFR mutations in lung cancer: correlation with clinical response to gefitinib therapy. Science. 2004; 304(5676):1497-1500.

14. Suda K, Tomizawa K, and Mitsudomi T. Biological and clinical significance of KRAS mutations in lung cancer: an oncogenic driver that contrasts with EGFR mutation. Cancer Metastasis Rev. 2010;29:49-60.

15. Mitsudomi T, Yatabe Y. Mutations of the epidermal growth factor receptor gene and related genes as determinants of epidermal growth factor receptor tyrosine kinase inhibitors sensitivity in lung cancer. Cancer Sci. 2007;98(12):1817-1824.

16. Fukuoka M, Wu YL, Thongprasert S, et al. Biomarker analyses and final overall survival results from a phase III, randomized, open-label, first-line study of gefitinib versus carboplatin/paclitaxel in clinically selected patients with advanced non-small-cell lung cancer in Asia (IPASS). J Clin Oncol. 2011;29(21):2866-2874.

17. Yang JC-H, Schuler MH, Yamamoto N, et al. LUX-Lung 3: a randomized, open-label, phase III study of afatinib versus pemetrexed and cisplatin as first-line treatment for patients with advanced adenocarcinoma of the lung harboring EGFR-activating mutations. American Society of Clinical Oncology (ASCO) Annual '12 Meeting, Chicago, Illinois, June 1-5, 2012. J Clin Oncol. 2012;30(Suppl: abstr LBA7500).

18. Wu YL, Zhou C, Hu C, et al. LUX-Lung 6: a randomized, open-label, phase III study of afatinib (A) versus gemcitabine/cisplatin (GC) as first-line treatment for Asian patients (pts) with EGFR mutation-positive (EGFR M+) advanced adenocarcinoma of the lung. American Society of Clinical Oncology (ASCO) Annual '13 Meeting, Chicago, Illinois, 31 May-4 June, 2013. J Clin Oncol. 2013;31(Suppl: abstr 8016).

19. Takano T, Fukui T, Ohe Y, et al. EGFR mutations predict survival benefit from gefitinib in patients with advanced lung adenocarcinoma: a historical comparison of patients treated before and after gefitinib approval in Japan. J Clin Oncol. 2008;26(34):5589-5595.

20. Suda K, Ito S, Mizuuchi H, Maehara Y, Yatabe Y, Mitsudomi T. EGFR tyrosine kinase inhibitors prolong overall survival in EGFR mutated non-small-cell lung cancer patients with postsurgical recurrence. J Can Res Updates. 2012;1(1):102-107. 
21. Schiller JH, Harrington D, Belani CP, et al; Eastern Cooperative Oncology Group. Comparison of four chemotherapy regimens for advanced non-small-cell lung cancer. $N$ Engl J Med. 2002;346(2): 92-98.

22. Toyooka S, Kiura K, Mitsudomi T. EGFR mutation and response of lung cancer to gefitinib. $N$ Engl J Med. 2005;352(20):2136; author reply 2136

23. Massarelli E, Johnson FM, Erickson HS, Wistuba II, Papadimitrakopoulou V. Uncommon epidermal growth factor receptor mutations in non-small cell lung cancer and their mechanisms of EGFR tyrosine kinase inhibitors sensitivity and resistance. Lung Cancer. 2013;80(3):235-241

24. Wu JY, Yu CJ, Chang YC, Yang CH, Shih JY, Yang PC. Effectiveness of tyrosine kinase inhibitors on "uncommon" epidermal growth factor receptor mutations of unknown clinical significance in non-small cell lung cancer. Clin Cancer Res. 2011;17(11):3812-3821.

25. Yatabe Y, Takahashi T, Mitsudomi T. Epidermal growth factor receptor gene amplification is acquired in association with tumor progression of EGFR-mutated lung cancer. Cancer Res. 2008;68(7): 2106-2111.

26. Yatabe Y, Matsuo K, Mitsudomi T. Heterogeneous distribution of EGFR mutations is extremely rare in lung adenocarcinoma. J Clin Oncol. 2011;29(22):2972-2977.

27. Engelman JA, Mukohara T, Zejnullahu K, et al. Allelic dilution obscures detection of a biologically significant resistance mutation in EGFRamplified lung cancer. J Clin Invest. 2006;116(10):2695-2706.

28. Parsons R. Human cancer, PTEN and the PI-3 kinase pathway. Semin Cell Dev Biol. 2004;15(2):171-176.

29. Sos ML, Koker M, Weir BA, et al. PTEN loss contributes to erlotinib resistance in EGFR-mutant lung cancer by activation of Akt and EGFR. Cancer Res. 2009;69(8):3256-3261.

30. Yano S, Yamada T, Takeuchi S, et al. Hepatocyte growth factor expression in EGFR mutant lung cancer with intrinsic and acquired resistance to tyrosine kinase inhibitors in a Japanese cohort. J Thorac Oncol. 2011;6(12):2011-2017.

31. Maheswaran S, Sequist LV, Nagrath S, et al. Detection of mutations in EGFR in circulating lung-cancer cells. $N$ Engl J Med. 2008; 359(4):366-377.

32. Rosell R, Molina MA, Costa C, et al. Pretreatment EGFR T790M mutation and BRCA1 mRNA expression in erlotinib-treated advanced non-small-cell lung cancer patients with EGFR mutations. Clin Cancer Res. 2011;17(5):1160-1168.

33. Su KY, Chen HY, Li KC, et al. Pretreatment epidermal growth factor receptor (EGFR) T790M mutation predicts shorter EGFR tyrosine kinase inhibitor response duration in patients with non-small-cell lung cancer. J Clin Oncol. 2012;30(4):433-440.

34. Faber AC, Corcoran RB, Ebi H, et al. BIM expression in treatment-naive cancers predicts responsiveness to kinase inhibitors. Cancer Discov. 2011;1(4):352-365.

35. Ng KP, Hillmer AM, Chuah CT, et al. A common BIM deletion polymorphism mediates intrinsic resistance and inferior responses to tyrosine kinase inhibitors in cancer. Nat Med. 2012;18(4):521-528.

36. Nakagawa T, Takeuchi S, Yamada T, et al. EGFR-TKI resistance due to BIM polymorphism can be circumvented in combination with HDAC inhibition. Cancer Res. 2013;73(8):2428-2434.

37. Bivona TG, Hieronymus H, Parker J, et al. FAS and NF-kappaB signalling modulate dependence of lung cancers on mutant EGFR. Nature. 2011;471(7339):523-526.

38. Karachaliou N, Costa C, Gimenez-Capitan A, et al; Spanish Lung Cancer Group. BRCA1, LMO4, and CtIP mRNA expression in erlotinib-treated non-small-cell lung cancer patients with EGFR mutations. $J$ Thorac Oncol. 2013;8(3):295-300.

39. Endoh H, Yatabe Y, Kosaka T, Kuwano H, Mitsudomi T. PTEN and PIK3CA expression is associated with prolonged survival after gefitinib treatment in EGFR-mutated lung cancer patients. $J$ Thorac Oncol. 2006;1(7):629-634.
40. Fujita Y, Suda K, Kimura H, et al. Highly sensitive detection of EGFR T790M mutation using colony hybridization predicts favorable prognosis of patients with lung cancer harboring activating EGFR mutation. J Thorac Oncol. 2012;7(11):1640-1644.

41. Rosell R, Molina MA, Taron M, et al. EGFR compound mutants discriminate survival on erlotinib in non-small-cell lung cancer (NSCLC) patients (p) in the EURTAC study. American Society of Clinical Oncology (ASCO) Annual '12 Meeting, Chicago, Illinois, 1-5 June, 2012. J Clin Oncol. 2012;30(Suppl: abstr 7522).

42. Lee JK, Shin JY, Kim S, et al. Primary resistance to epidermal growth factor receptor (EGFR) tyrosine kinase inhibitors (TKIs) in patients with non-small-cell lung cancer harboring TKI-sensitive EGFR mutations: an exploratory study. Ann Oncol. Epub April 4, 2013.

43. Jackman D, Pao W, Riely GJ, et al. Clinical definition of acquired resistance to epidermal growth factor receptor tyrosine kinase inhibitors in non-small-cell lung cancer. J Clin Oncol. 2010;28(2): $357-360$.

44. Kobayashi S, Boggon TJ, Dayaram T, et al. EGFR mutation and resistance of non-small-cell lung cancer to gefitinib. $N$ Engl J Med. 2005;352(8):786-792.

45. Pao W, Miller VA, Politi KA, et al. Acquired resistance of lung adenocarcinomas to gefitinib or erlotinib is associated with a second mutation in the EGFR kinase domain. PLoS Med. 2005;2(3):e73.

46. Arcila ME, Oxnard GR, Nafa K, et al. Rebiopsy of lung cancer patients with acquired resistance to EGFR inhibitors and enhanced detection of the T790M mutation using a locked nucleic acid-based assay. Clin Cancer Res. 2011;17(5):1169-1180.

47. Suda K, Onozato R, Yatabe Y, Mitsudomi T. EGFR T790M mutation: a double role in lung cancer cell survival? J Thorac Oncol. 2009;4(1):1-4.

48. Engelman JA, Zejnullahu K, Mitsudomi T, et al. MET amplification leads to gefitinib resistance in lung cancer by activating ERBB3 signaling. Science. 2007;316(5827):1039-1043.

49. Bean J, Brennan C, Shih JY, et al. MET amplification occurs with or without T790M mutations in EGFR mutant lung tumors with acquired resistance to gefitinib or erlotinib. Proc Natl Acad Sci U S A. 2007; 104(52):20932-20937.

50. Yano S, Wang W, Li Q, et al. Hepatocyte growth factor induces gefitinib resistance of lung adenocarcinoma with epidermal growth factor receptor-activating mutations. Cancer Res. 2008;68(22): 9479-9487.

51. Suda K, Murakami I, Katayama T, et al. Reciprocal and complementary role of MET amplification and EGFR T790M mutation in acquired resistance to kinase inhibitors in lung cancer. Clin Cancer Res. 2010;16(22):5489-5498.

52. Garofalo M, Romano G, Di Leva G, et al. EGFR and MET receptor tyrosine kinase-altered microRNA expression induces tumorigenesis and gefitinib resistance in lung cancers. Nat Med. 2011;18(1): 74-82.

53. Sequist LV, Waltman BA, Dias-Santagata D, et al. Genotypic and histological evolution of lung cancers acquiring resistance to EGFR inhibitors. Sci Transl Med. 2011;3(75):75ra26.

54. Suda K, Mizuuchi H, Maehara Y, Mitsudomi T. Acquired resistance mechanisms to tyrosine kinase inhibitors in lung cancer with activating epidermal growth factor receptor mutation-diversity, ductility, and destiny. Cancer Metastasis Rev. 2012;31(3-4):807-814.

55. Takezawa K, Pirazzoli V, Arcila ME, et al. HER2 amplification: a potential mechanism of acquired resistance to EGFR inhibition in EGFR-mutant lung cancers that lack the second-site EGFRT790M mutation. Cancer Discov. 2012;2(10):922-933.

56. Zhang Z, Lee JC, Lin L, et al. Activation of the AXL kinase causes resistance to EGFR-targeted therapy in lung cancer. Nat Genet. 2012;44(8):852-860.

57. Ercan D, Xu C, Yanagita M, et al. Reactivation of ERK signaling causes resistance to EGFR kinase inhibitors. Cancer Discov. 2012 2(10):934-947. 
58. Ohashi K, Sequist LV, Arcila ME, et al. Lung cancers with acquired resistance to EGFR inhibitors occasionally harbor BRAF gene mutations but lack mutations in KRAS, NRAS, or MEK1. Proc Natl Acad Sci US A. 2012;109(31):E2127-E2133.

59. Tabara K, Kanda R, Sonoda K, et al. Loss of activating EGFR mutant gene contributes to acquired resistance to EGFR tyrosine kinase inhibitors in lung cancer cells. PloS One. 2012;7(7):e41017.

60. Shien K, Toyooka S, Yamamoto H, et al. Acquired resistance to EGFR inhibitors is associated with a manifestation of stem cell-like properties in cancer cells. Cancer Res. 2013;73(10):3051-3061.

61. Yu HA, Arcila ME, Rekhtman N, et al. Analysis of tumor specimens at the time of acquired resistance to EGFR-TKI therapy in 155 patients with EGFR-mutant lung cancers. Clin Cancer Res. 2013; 19(8):2240-2247.

62. Engelman JA, Zejnullahu K, Gale CM, et al. PF00299804, an irreversible pan-ERBB inhibitor, is effective in lung cancer models with EGFR and ERBB2 mutations that are resistant to gefitinib. Cancer Res. 2007;67(24):11924-11932.

63. Li D, Ambrogio L, Shimamura T, et al. BIBW2992, an irreversible EGFR/HER2 inhibitor highly effective in preclinical lung cancer models. Oncogene. 2008;27(34):4702-4711.

64. Janne PA, Schellens JH, Engelman JA, et al. Preliminary activity and safety results from a phase I clinical trial of PF-00299804, an irreversible pan-HER inhibitor, in patients (pts) with NSCLC. J Clin Oncol. 2008;26(Suppl: abstr 8027).

65. Miller VA, Hirsh V, Cadranel J, et al. Afatinib versus placebo for patients with advanced, metastatic non-small-cell lung cancer after failure of erlotinib, gefitinib, or both, and one or two lines of chemotherapy (LUX-Lung 1): a phase 2b/3 randomised trial. Lancet Oncol. 2012;13(5):528-538.

66. Zhou W, Ercan D, Chen L, et al. Novel mutant-selective EGFR kinase inhibitors against EGFR T790M. Nature. 2009;462:1070-1074.

67. Ohashi K, Suda K, Sun J, et al. CNX-2006, a novel irreversible epidermal growth factor receptor (EGFR) inhibitor, selectively inhibits EGFR T790M and fails to induce T790M-mediated resistance in vitro. Proceedings of the 104th Annual Meeting of the American Association for Cancer Research, Washington, DC., Philadelphia, April 6-10, 2013. 2101A.

68. Lee HJ, Schaefer G, Heffron TP, et al. Noncovalent wild-type-sparing inhibitors of EGFR T790M. Cancer Discov. 2013;3(2):168-181.

69. Sequist LV, Soria JC, Gadgeel SM, et al. First-in-human evaluation of CO-1686, an irreversible, selective, and potent tyrosine kinase inhibitor of EGFR T790M. American Society of Clinical Oncology (ASCO) Annual '13 Meeting, Chicago, Illinois, 31 May-4 June, 2013. J Clin Oncol. 2013;31(Suppl: abstr 2524).

70. Chmielecki J, Foo J, Oxnard GR, et al. Optimization of dosing for EGFR-mutant non-small cell lung cancer with evolutionary cancer modeling. Sci Transl Med. 2011;3(90):90ra59.

71. Das Thakur M, Salangsang F, Landman AS, et al. Modelling vemurafenib resistance in melanoma reveals a strategy to forestall drug resistance. Nature. 2013;494(7436):251-255.

72. Inoue A, Kobayashi K, Maemondo M, et al. Updated overall survival results from a randomized phase III trial comparing gefitinib with carboplatin-paclitaxel for chemo-naive non-small cell lung cancer with sensitive EGFR gene mutations (NEJ002). Ann Oncol. 2013;24(1):54-59.

73. Riely GJ, Kris MG, Zhao B, et al. Prospective assessment of discontinuation and reinitiation of erlotinib or gefitinib in patients with acquired resistance to erlotinib or gefitinib followed by the addition of everolimus. Clin Cancer Res. 2007;13(17):5150-5155.

74. Chaft JE, Oxnard GR, Sima CS, Kris MG, Miller VA, Riely GJ. Disease flare after tyrosine kinase inhibitor discontinuation in patients with EGFR-mutant lung cancer and acquired resistance to erlotinib or gefitinib: implications for clinical trial design. Clin Cancer Res. 2011;17(19):6298-6303.
75. AstraZeneca. A Study of IRESSA Treatment Beyond Progression in Addition to Chemotherapy Versus Chemotherapy Alone (IMPRESS). Available from: http://clinicaltrials.gov/show/NCT01544179. NLM identifier: NCT01544179. Accessed July 17, 2013.

76. Regales L, Gong Y, Shen R, et al. Dual targeting of EGFR can overcome a major drug resistance mutation in mouse models of EGFR mutant lung cancer. J Clin Invest. 2009;119(10):3000-3010.

77. Janjigian YY, Smit E, Horn L, et al. Activity of afatinib/cetuximab in patients with EGFR mutant non-small cell lung cancer (NSCLC) and acquired resistance to EGFR inhibitors. European Society for Medical Oncology (ESMO) 2012 Congress Vienna, Austria, 28 September-2 October, 2012. Ann Oncol. 2012;23: abstr 12270 .

78. Kobayashi N, Toyooka S, Soh J, et al. The anti-proliferative effect of heat shock protein 90 inhibitor, 17-DMAG, on non-small-cell lung cancers being resistant to EGFR tyrosine kinase inhibitor. Lung Cancer. 2012;75(2):161-166.

79. Shimamura T, Li D, Ji H, et al. Hsp90 inhibition suppresses mutant EGFR-T790M signaling and overcomes kinase inhibitor resistance. Cancer Res. 2008;68(14):5827-5838.

80. Pignon JP, Tribodet H, Scagliotti GV, et al; LACE Collaborative Group. Lung adjuvant cisplatin evaluation: a pooled analysis by the LACE Collaborative Group. J Clin Oncol. 2008;26(21):3552-3559.

81. Mitsudomi T, Suda K, Yatabe Y. Surgery for NSCLC in the era of personalized medicine. Nat Rev Clin Oncol. 2013;10(4): 235-244.

82. Goss GD. A phase III randomized, double-blind, placebo-controlled trial of the epidermal growth factor receptor inhibitor gefitinib in completely resected stage IB-IIIA non-small cell lung cancer (NSCLC): NCIC CTG BR.19. American Society of Clinical Oncology (ASCO) Annual '10 Meeting, Chicago, Illinois, 4-8 June, 2010. J Clin Oncol. 2010;28(Suppl: abstr LBA7005).

83. D'Angelo SP, Janjigian YY, Ahye N, et al. Distinct clinical course of EGFR-mutant resected lung cancers: results of testing of 1118 surgical specimens and effects of adjuvant gefitinib and erlotinib. $J$ Thorac Oncol. 2012;7(12):1815-1822.

84. A randomized phase III trial of adjuvant gefitinib versus cisplatin and vinorelbine in completely resected (stage II-III) non-small cell lung cancer (NSCLC) patients with mutated EGFR (investigator-initiated multicenter clinical trial) Available from: https://upload.umin.ac.jp/ cgi-open-bin/ctr/ctr.cgi?function=brows\&action=brows\&recptno $=$ R0 $00007398 \&$ type $=$ summary\&language $=$ E Identifier: UMIN000006252. Accessed July 24, 2013.

85. Intergroupe Francophone de Cancerologie Thoracique. TAilored Post-Surgical Therapy in Early Stage NSCLC (TASTE). Available from: http://clinicaltrials.gov/show/NCT00775385. NLM identifier: NCT00775385. Accessed July 24, 2013.

86. Mok TS, Wu YL, Thongprasert S, et al. Gefitinib or carboplatinpaclitaxel in pulmonary adenocarcinoma. $N$ Engl J Med. 2009; 361(10):947-957.

87. Han JY, Park K, Kim SW, et al. First-SIGNAL: first-line singleagent iressa versus gemcitabine and cisplatin trial in never-smokers with adenocarcinoma of the lung. J Clin Oncol. 2012;30(10): 1122-1128.

88. Isobe K, Hata Y, Kaburaki K, et al. Clinical significance of BIM deletion polymorphism in non-small cell lung cancer with epidermal growth factor receptor mutation. American Society of Clinical Oncology (ASCO)Annual '13 Meeting, Chicago, Illinois, 31 May-4 June, 2013. J Clin Oncol. 2013; 31(Suppl: abstr 11052).

89. Horiike A, Nishio M, Goto K, et al. A phase II study of erlotinib as first-line treatment in Japanese advanced NSCLC patients harboring EGFR mutations. European Society for Medical Oncology (ESMO) 2012 Congress Vienna, Austria, 28 September-2 October, 2012. Ann Oncol. 2012;23(Suppl 9):ix413; abstr 1260P. 


\section{Publish your work in this journal}

Lung Cancer: Targets and Therapy is an international, peer-reviewed, open access journal focusing on lung cancer research, identification of therapeutic targets and the optimal use of preventative and integrated treatment interventions to achieve improved outcomes, enhanced survival and quality of life for the cancer patient Specific topics covered in the journal include: Epidemiology, detection and screening; Cellular research and biomarkers; Identification of biotargets and agents with nove mechanisms of action; Optimal clinical use of existing anticancer agents, including combination therapies; Radiation and surgery; Palliative care; Patient adherence, quality of life, satisfaction; Health economic evaluations. The manuscript management system is completely online and includes a very quick and fair peer-review system. Visit http://www.dovepress.com/testimonials.php to read real quotes from system. Visit http:/
published authors. 